\title{
Application of the revised International Prognostic Scoring System for myelodysplastic syndromes in Argentinean patients
}

\author{
Carolina B. Belli • Yesica Bestach • Mario Giunta • Marcelo Iastrebner • \\ Isabel Santos • Noemí Pintos • Jorge Arbelbide • Ana L. Basquiera • \\ Raquel Bengió • Irene Larripa
}

Received: 9 December 2012 / Accepted: 15 July 2013 / Published online: 28 July 2013

(C) Springer-Verlag Berlin Heidelberg 2013

\section{Dear Editor,}

The International Prognostic Scoring System (IPSS) [1], the gold standard for risk assessment in myelodysplastic syndromes (MDS), has been recently revised (IPSS-R). The authors proposed a new prognostic model including novel components: five cytogenetic prognostic subgroups with specific classification of a number of less common cytogenetic subsets $[2,3]$; the $<5 \%$ bone marrow blasts category was split between $0-2 \%$ and $>2-<5 \%$; depth of cytopenias at clinically relevant cut-points for haemoglobin level, platelet count, and absolute neutrophil count [2]. As the score [2] was established in MDS patients including all French-American-British classification subtypes [4], the aim of this study was to

C. B. Belli, M. Iastrebner, I. Santos, N. Pintos, J. Arbelbide, A. L. Basquiera on behalf of the Argentinean MDS Study Group, Argentinean Society of Haematology, Argentina

Electronic supplementary material The online version of this article (doi:10.1007/s00277-013-1848-4) contains supplementary material, which is available to authorized users.

\section{B. Belli $(\bowtie) \cdot$ Y. Bestach · I. Larripa}

Laboratorio de Genética Hematológica, Instituto de Medicina Experimental/ Consejo Nacional de Investigaciones Científicas y

Técnicas (IMEX/ CONICET), Academia Nacional de Medicina (ANM), Pacheco de Melo 3081, 1425 Buenos Aires, Argentina e-mail: cbelli@hematologia.anm.edu.ar

\section{Giunta}

Instituto Privado de Hematología y Hemoterapia, Paraná, Argentina

\section{Iastrebner}

Servicio de Hematología, Centro Médico "San Luis",

Buenos Aires, Argentina

\section{Santos}

Servicio de Hematología, Hospital Militar Central "Dr. Cosme

Argerich", Buenos Aires, Argentina

\section{N. Pintos}

Servicio de Hematología, Sanatorio "Julio Méndez", Buenos Aires, Argentina apply the IPSS-R in Argentinean MDS patients classified according to the World Health Organization (WHO) classification [5].

We retrospectively analysed a cohort of 371 de novo MDS patients [6] diagnosed between 1981 and 2012. According to the WHO classification, 43 patients were classified as refractory cytopenia with unilineage dysplasia/ refractory anaemia with ringed sideroblasts, 17 as del(5q) syndrome, 201 as refractory cytopenia with multilineage dysplasia, 44 as RAEB type 1, and 66 as RAEB type 2 . The median age was 70 (17-92) years with $72 \%$ of patients above 60 , the gender ratio was 1.4 (M/F: 214/ 157), and 157 (42\%) patients showed an abnormal karyotype. During the follow-up (median 23.3 months), 80 (22\%) showed

J. Arbelbide

Servicio de Hematología, Hospital Italiano de Buenos Aires, Buenos Aires, Argentina

\section{A. L. Basquiera}

Servicio de Hematología y Oncología, Hospital Privado de Córdoba, Córdoba, Argentina

R. Bengió

Departamento de Hemato-Oncología, Instituto de Investigaciones Hematológicas (IIHEMA)/ ANM, Buenos Aires, Argentina

I. Larripa

Departamento de Genética, IIHEMA/ ANM, Buenos Aires, Argentina 
leukemic progression and 161 (43\%) died (median overall survival: 55.5 months).

Studied variables (gender and WHO classification, percentage of bone marrow blast, cytogenetic risk category, and depth of cytopenias according to the IPSS-R [2]), and the IPSS [1], IPSS-R (Fig. 1a-b), and IPSS-R adjusted by age (Fig. 1c) [2] systems showed statistical differences for predicting both overall survival and leukemic evolution (see Electronic supplementary material, ESM). Patients were classified by the IPSS-R as very low (23\%), low (40\%), intermediate (15\%), high (14\%), and very high risk ( $9 \%)$, with median survival of 125, 62, 44, 19, and 15 months (Fig. 1a), and time to leukemic evolution ( $25 \%)$ of $>150,131,51,6$, and 5 months, respectively (Fig. 1b). The proposed IPSS-R defines a new intermediate risk group mainly composed by patients from the intermediate-1 IPSS risk category $(84 \%, 47 / 56)$ and allowed us to identify $7 \%(11 / 150)$ of patients that were shifted from the intermediate-1 risk group into the high IPSS-R risk group.
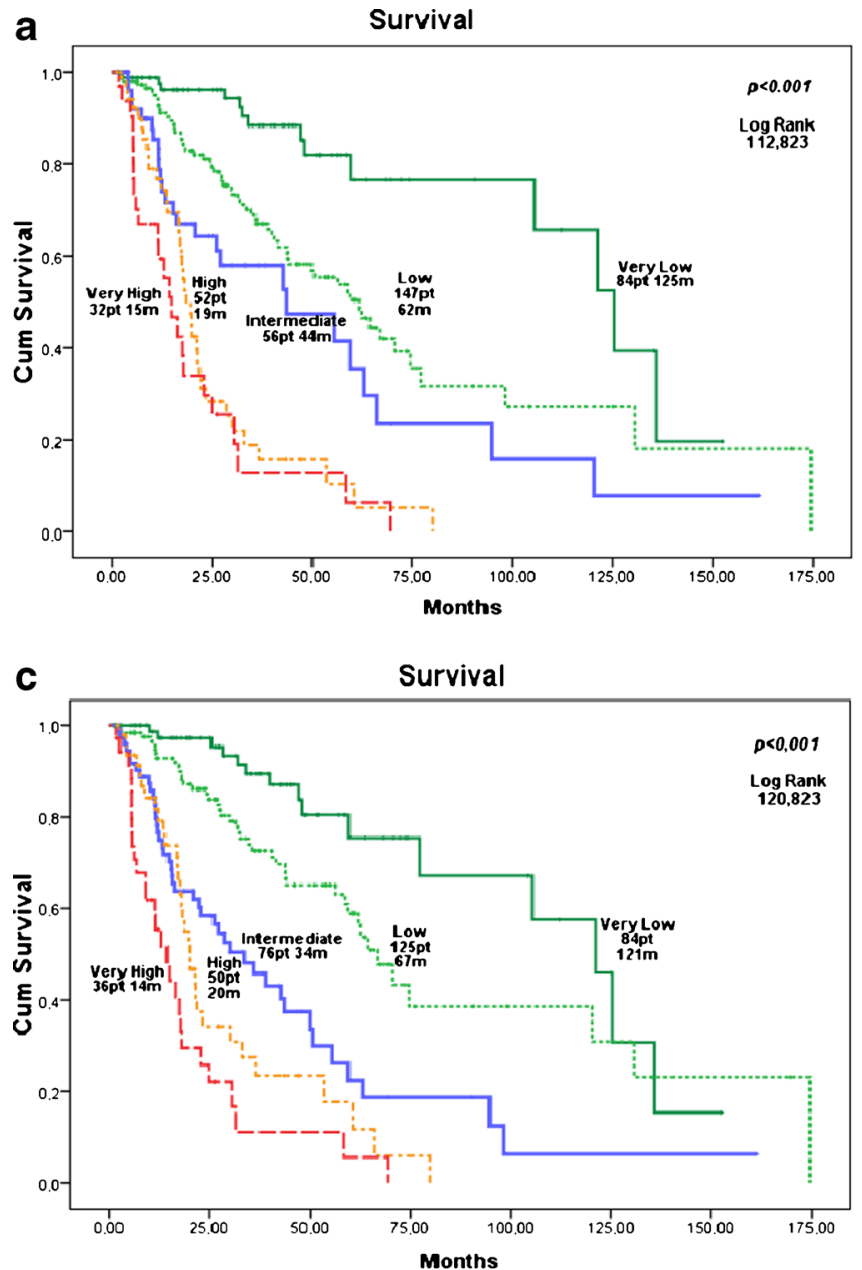

Fig. 1 Prognostic relevance of the IPSS-R group of risk in the Argentinean cohort of MDS patients classified by WHO. Kaplan-Meier plots for a survival according to the IPSS-R, $\mathbf{b}$ progression to acute myeloid leukaemia (AML), c survival related to their respective age-adjusted
Although limit age of 60 years did not show statistical differences for predicting survival, our results confirm that younger good risk patients have significantly better prognosis than elderly counterparts (very low/low risk patients: $125 \mathrm{vs.}$ 64 months, $p=0.014$ ), while the age at diagnosis has no impact on disease outcome for higher risk patients $[1,2$, $7,8]$. The proposed formula for an age-adjusted categorization [2] helped us to identify $19 \%(28 / 147)$ of short surviving patients among low risk IPSS-R patients with a median survival of 34 months (Fig. 1d). These patients showed, among relevant parameters, a gender ratio $\mathrm{M} / \mathrm{F}$ of 3.0 , a median age of 81 years, $2.5 \%$ of BM blasts, and $9.1 \mathrm{~g} / \mathrm{dL}$ of haemoglobin level; 12 (43\%) presented an abnormal karyotype and 17 died, including 6 patients with previous leukemic progression.

It can be concluded that the IPSS-R system is simple to use since includes accessible variables showing a good reproducibility, effectiveness in predicting clinical outcome, and a refinement of the intermediate risk category in our WHO classified series.
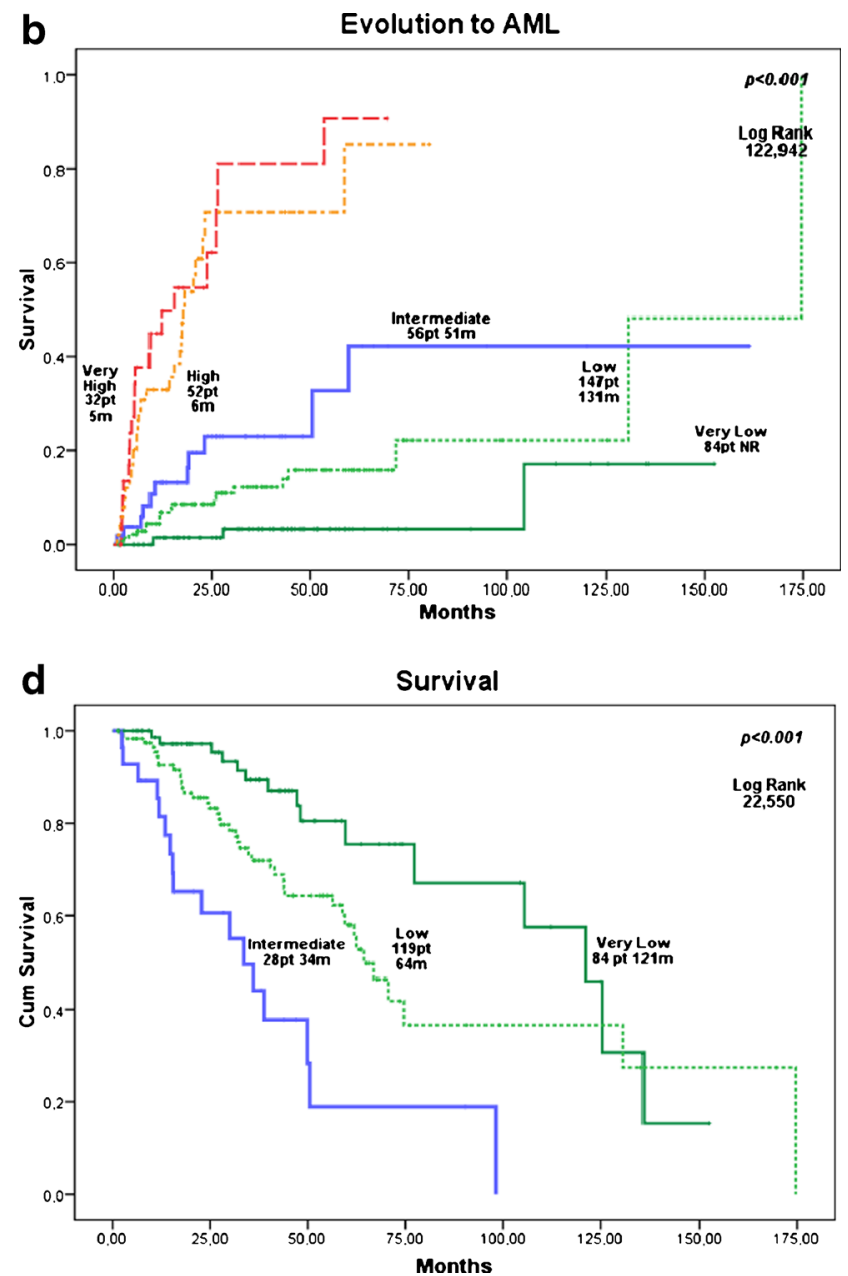

IPSS-R group of risk for the overall population, and $\mathbf{d}$ for the very low/ low risk group of patients. Number of patient and median overall survival or the time to $25 \%$ to AML evolution for each group of risk are shown 
Acknowledgements The authors would like to thank the investigators of the Argentinean MDS's Study Group belonging to the Argentinean Society of Haematology for providing information from the MDS Registry database. This paper was supported by Argentinean grants from the Consejo Nacional de Investigaciones Cientificas y Técnicas (CONICET) and the Agencia Nacional de Promoción Científica y Tecnológica (ANPCyT).

Ethical statement All procedures followed were in accordance with the ethical standards of the responsible committee on human experimentation (institutional and national) and with the Helsinki Declaration of 1975 , as revised in 2008 (5). Informed consent was obtained from all patients for being included in the study.

Conflict of interest The authors declare that they have no conflict of interest.

\section{References}

1. Greenberg P, Cox C, LeBeau M, Fenaux P, Morel P, Sanz G et al (1997) International Scoring System for evaluating prognosis in myelodysplastic syndromes. Blood 89(6):2079-2088
2. Greenberg PL, Tuechler H, Schanz J, Sanz G, Garcia-Manero G, Solé F et al (2012) Revised International Prognostic Scoring System for myelodysplastic syndromes. Blood 120(12):2454-2465

3. Schanz J, Tüchler H, Solé F, Mallo M, Luño E, Cervera J et al (2012) New comprehensive cytogenetic scoring system for primary myelodysplastic syndromes (MDS) and oligoblastic acute myeloid leukemia after MDS derived from an international database merge. $\mathrm{J}$ Clin Oncol 30(8):820-829

4. Bennett J, Catovsky D, Daniel M, Galton D, Gralnick H, Sultan C (1982) Proposals for the classification of the myelodysplastic syndromes. Br J Haematol 51(2):189-199

5. Vardiman J, Thiele J, Arber D, Brunning RD, Borowitz MJ, Porwit A et al (2009) The 2008 revision of the World Health Organization (WHO) classification of myeloid neoplasms and acute leukemia: rationale and important changes. Blood 114(5):937-951

6. Valent P, Horny HP, Bennett JM, Fonatsch C, Germing U, Greenberg P et al (2007) Definitions and standards in the diagnosis and treatment of the myelodysplastic syndromes: consensus statements and report from a working conference. Leuk Res 31(6):727-736

7. Kuendgen A, Strupp C, Aivado M, Hildebrandt B, Haas R, Gattermann N, Germing U (2006) Myelodysplastic syndromes in patients younger than age 50. J Clin Oncol 24(34):5358-5365

8. Nösslinger T, Tüchler H, Germing U, Sperr WR, Krieger O, Haase D et al (2010) Prognostic impact of age and gender in 897 untreated patients with primary myelodysplastic syndromes. Ann Oncol 21(1):120-125 